\title{
Regulatory Obligations Of The Electronic Communications Market, Administrative And Judicial Appeal, And Monitoring: Inspection And Sanctions In Albania
}

\author{
Jonida Gjika, PhD \\ Electronic Communications and Postal Authority of Albania
}

doi: 10.19044/esj.2016.v12n7p470 URL:http://dx.doi.org/10.19044/esj.2016.v12n7p470

\begin{abstract}
Electronic communications services and the dynamics of their development require in itself special care and continuous efforts of the national policies. This is used to build effective strategies with the aim of laying the right steps. It is in coherence with international development of the electronic communications market for the products. It also serves as an integral part of its services.

Some of the decision which will result to measurable effects in the market include: concrete steps which are related to the harmonization and alignment of the full legislation national primary, absorption and outline of the directives of the EU as an integral part thereof, drafting regulatory acts as secondary legislation, and continuous care for a hand regulatory which is strong and neutral.

For careful coordination of the chains as a whole in the chain functioning of this market, where policies and sectoral strategies, regulatory and decisionmaking, entrepreneurs and consumers in the market of products/services offered are on the side of maximum benefits, it would first of all mean finding the appropriate instruments and implement them in a legal manner. This is possible through effective remedies. Thus, the development of competition is the only way that would make it possible for all the actors to find themselves on the side of the party that would win.
\end{abstract}

Keywords: Liabilities, regulatory complaint, monitoring, inspection, market sanctions.

\section{Introduction}

The electronic communication market is undergoing development and effective competition. However, this was despite incentives to the internal market itself. Weight defining key players with influence in this 
aspect such as liberalization, investment and regulation, makes it possible to carry out concrete steps to jump using remedies. These remedies allow the implementation of regulatory obligations imposed in this market.

In essence, the national legal framework for the electronic communications sector as a going concern has been adapted and harmonized gradually over the years. Thus, this was done with the regulatory framework of the EU for this sector. The transposition core of EU Directives ${ }^{19}$, which includes the amendments in subsequent years, has a starting set of directives. These include: Directive 2002/21/EC as amended by Directive 2009/140/ EC, Directive 2002/19/EC as amended by Directive 2009/140/EC, Directive 2002/20/EC as amended by Directive 2009/140/EC, Directive 2002/22/ EC as amended by Directive 2009/136/EC, Directive 2002/58/EC as amended by Directive 2009/136/EC, and Directive 2006/24/EC. Therefore, in their entirety, some of the improvement done on these Directives include: Framework of Authorization, Framework of Universal Service, Framework of Access and Interconnection, Framework of Data Protection, and Framework of Policy Spectrum and finite resources. Furthermore, they were into secondary regulatory acts, which when considered together, constitutes the group of remedies for the establishment and implementation of regulatory obligations.

Basically, regulatory obligations imposed on the electronic communications market have their procedure defined in the law, their respective field, ${ }^{20}$ and the regulatory acts which is relevant. Consequently, in summary, it could be identified as regulatory obligations to settle entrepreneurs who have a significant power in the market. Determination is done after performing the process of market analysis. Therefore, it is not the only process that enables the imposition of regulatory obligations. This is because the legal provisions of the field have created the space necessary for the imposition of regulatory obligations in the absence status. Furthermore, this is with significant power in the market for entrepreneurs who exercise their activity in this market. It is also defined as a legal instrument in the hands of the regulator to impose group regulatory obligations for specific conditions laid down in the law field and conditioned as follows: a) the undertaking is granted the right to use it frequently according to the law definitions; b) in the establishment of regulatory obligations, it is necessary to ensure the normal operation of networks; and c) the establishment of

\footnotetext{
${ }^{19}$ Directive 2002/21/EC as amended by Directive 2009/140/ EC, Directive 2002/19/ EC as amended by Directive 2009/140/ EC, Directive 2002/20/ EC as amended by Directive 2009/140 / EC, Directive 2002/22/ EC as amended by Directive 2009/136 / EC, Directive 2002/58/ EC as amended by Directive 2009/136 / EC, and Directive 2006/24 / EC.

${ }^{20}$ Law no. 9918, dated 19. 05. 2008 "On Electronic Communications in the Republic of Albania"amended;
} 
regulatory obligations are required to meet international commitments. Therefore, for the imposition of regulatory obligations, one of the main stages is to assess and care for the basic principle of the law. These entails that the competition in this market is been harmonized in a prudent way. In addition, it considers the proportionality and transparency of placing these obligations in relation to the problem/problems identified and the intended solution to the problem/problems.

Legal provisions in the sector of electronic communications enable the deployment of special obligations. However, these obligations are not included as group obligations in the conditions set out in the authorization given for the provision of electronic communications services for entrepreneurs. Above all, it uses an advisory group process of regulatory measures intended to be placed on the market. They are grouped as obligations for the provision of universal service. Also, it serves as specific obligations for undertakings with significant power in the relevant markets. Simply put, the regulatory obligations imposed on the electronic communications market for entrepreneurs, offers products/ services in this market which are categorized into two groups. Firstly, it involves the obligations imposed by following a process of analysis and review of relevant markets. Secondly, it involves special obligation to the conditions for entrepreneurs with significant market power. Thus, this also includes the group of obligations for entrepreneurs who do not have significant power status.

\section{Implementation of the Necessary Regulatory Obligations and Remedies}

Review processes, markets, analyzing them, and identifying potential problems as an obstacle to the proper development of positive competition in these markets, provides, inter alia, the group of regulatory obligations necessary to solve or to diminish the problems identified. This is decided on a timetable which will be monitored. Thus, the focus of the monitoring process will be the evaluation of the impact produced by the obligations imposed. Depending on the impact produced by the implementation of regulatory obligations set and phase, which entails the development of competition in the respective host implemented obligations, what is equally important is the next stage. Subsequently, this next stage requires a review of markets and regulatory measures to understand the need for continuity of the obligations imposed or withdraw.

Legal provisions in the sector provide the law to the two cases cited above. Thus, there was no narrow space of regulatory action to uphold the existing obligations. These existing obligations include adding or removing the obligations required or considered surplus, or making modifications which is different from the existing obligations. 
The list of markets necessary for review and the detailed analysis has changed in different periods of time. Therefore, this can be defined as the list binding all the member countries of the EU. Other countries aim at these membership lists of markets and relevant recommendations that accompany the list for the year 2003, 2007, and 2014. Furthermore, it served as a compass orientation starting with the list of the 18 markets in 2003; then in 7 markets in 2007, and finally 5 markets in 2014 which is important for their review and analysis.

The fact that the list of markets have referred to a number of markets for playback on any of the recommendations relevant to each period cited above, have not excluded the possibility of analysis and the review of other markets outside the reference list. This depends on the national circumstances of each country. Also, it is in accordance with the stage of development of the respective markets.

In a split second, the internal list of markets which were referred to analysis and review were classified as market level wholesale markets. In addition, based on the level of retail, such classification does not mean the term "classic" used as "Wholesale" or "retail sale". Fundamentally, this can be defined by the access given to other providers who are also known as the level of the majority. Then, resale of products/services in this market was made. Also, the level of accessibility was also ascertained. Thus, this is connected directly to the user of the product/service and is better known as the retail level for the products/ services offered.

Therefore, depending on the markets that intervene or settle regulatory charges, these kinds of obligations are also classified. Principally, markets at the level of the majority are under the weight of regulatory obligations such as award access, non-discrimination, transparency, definition of prices, and separation of accounts. On the other hand, markets level retail is protected by regulatory obligations. In addition, it requires the need of such intervention. The obligations imposed on wholesale markets level do not give proper effect. Also, we observed the level of retail markets where products/services to this market are visible by consumers.

The nature of regulatory obligations at the retail level is associated with obligations to award access, control prices, and offer quality product/ service. Remedies retail may include requirements which shows that the entrepreneur/ entrepreneurs, with significant power in the market, do not inhibit market entry or restrict competition by setting prices higher or have a discriminatory nature. However, this is seen in cases and identification that show preference to unnecessary specific end users or unreasonable services. Consequently, these services are detrimental to the development of competition. Also, the main purpose of the use of remedies at the retail level has inhibiting conduct which is anti-competitive. It utilizes direct market 
power or dominance that potential entrepreneurs/entrepreneurs at the expense of consumers, makes it possible to correct the problem that way, as well as the competition problems identified in the analysis of the market.

\section{The Administrative and Judicial Monitoring: Inspection and Sanctions}

Implementation of the regulatory obligations imposed, constitutes an important stage. Thus, it is clear that entrepreneurs in the electronic communications market would not like their implementation deliberately. This is in terms of the lack of enforcement and legal sanctions necessary in accompanying this stage. Legal provisions in the sector have enabled the existence of administrative links that are part of the regulator of the field. This is done through the process of monitoring and inspection to identify and define the time phases in which the implementation of regulatory obligations imposed, is associated with measuring their respective impact.

The process of monitoring and inspection is carried out through legal procedures and on the basis of a clear program. Also, it was developed with concrete objectives for the purpose of monitoring and inspection. This was supported by a team of experts in the field and decisions coherent followers and regulatory relevant obligations. It considers clearly the importance of regulatory obligations and their implementation, the rights and obligations of entrepreneurs, and the decision-making stages of appeal to the regulatory obligations imposed.

However, remedies and respective sanctions enable the proper implementation and timely regulatory obligations imposed. There is an important factor in this sector "in implementation time". Thus, this is because the electronic communications market is one of the most dynamic markets, and it is rapidly evolving. This was such that it would not be considered as a phase necessary to commence the implementation of regulatory obligations imposed, phase related directly after the administrative appeal, and an unfinished process of appealing to a court. Then, the situation in the electronic communications market can ward in a discrepancy between the regulatory obligations rated. This is needed to be established to correct the problem/ problems identified in the market with their implementation phase. However, this is because at a time subsequent to the probability of pushing in the medium to long term, it would pose a serious problem towards the development of competition in this market. In addition, it would also create an unsafe environment for business development in this sector.

Legal provisions in the sector of electronic communications have enabled a defined timetable for the review of complaints that would be coming from entrepreneurs in the market of electronic communications. These complaints are with regards to regulatory charges imposed, or the 
decisions of other regulatory issues related to entrepreneurship and their activity in this sector.

Material legal provisions in the legislation in the field of electronic communications and regulatory documents issued for this purpose for administrative appeals, administrative proceedings, investigative procedures, and the validity of administrative acts fully complies with normative provisions of the Code of Administrative Procedure ${ }^{21}$.

Administrative complaint is regarded as a legal tool in the hands of entrepreneurs to oppose regulatory decision-making. However, through the decision making, we requested the repeal, revocation, or modification of the act. Decision- regulatory in many cases has changed completely or partly by reviewing their complaints process as administrative. Thus, this is not to be considered as a process that is unreal, as long as troops which review the administrative appeal is just the same corps that adopted the challenged decision making. After then, the administrative act itself is issued.

Basically, administrative complaint constitutes an important instrument to control administrative activity and identifies it as an additional instrument in the hands of entrepreneurs. Therefore, any interested party which opposes the illegality or irregularity of an administrative act, considers the revocation of illegal administrative body for the issuance of the act. In this way, it serves as an appeal to important constitutional principle.

In the market of electronic communications, administrative appeal process or otherwise appeals process has seen its main form that has to do with the administrative appeal body which issued the act. This is regarded as the Steering Board by all the procedural and substantive rules. Review on its activities during the administrative complaint process, made a preliminary assessment of the regularity of a formal complaint from the point of view. Furthermore, its content was essentially examined. The decisions taken by the review body are considered to be final appeal bearing the obligation to provide administrative solution to the conflict it produced by itself.

The effect of administrative appeal is expressed as the suspension of the implementation of administrative act. Hence, this makes it possible that while examining the validity of the act body, all the legal effects of the act object was suspended until final resolution of the case in the administrative order.

After the closing phase of reviewing the administrative complaint on the decision that is relevant, it relates to regulatory obligations established in the market. It also relates with other issues on regulatory imposed on the market and entrepreneurs of electronic communications. Thus, this was embodied in decision making relevant regulations without denying the right

\footnotetext{
${ }^{21}$ Code of Administrative Procedure of the Republic of Albania, amended.
} 
attendance of complaints in judicial jurisdiction for the enterprise to be under the effects of regulatory obligations accommodated. Therefore, it becomes an enforceable obligation which is so imperative. Consequently, these obligations are subject of the work of administrative structures in monitoring - inspecting. In addition, they are part of the field of legal sanctions in the case of failure.

Entrepreneurs have the right to exercise all legal recourse complaining to the search mechanism compensatory, especially if the regulatory obligations are related to financial effects. This is also observed at the beginning of the implementation phase. Immediately after reviewing, the administrative complaint has special importance to guarantee the effectiveness of regulatory obligations on a timely basis. Thus, this is in relation with the purpose of the set and the size of the problem identified; otherwise, their application, with time, would not meet the intended purpose.

Sanctions provided by the law of the field are closely related to violation. Therefore, the penalty set is the subject of the work of inspectors of public regulatory authority. They make the proposal to the Governing Council for violation, and the size of the fine under the respective legal provisions. The sanctions provided by the law just do not have the nature of "fine" expressed in financial value. However, in relation to the violation and the repetition of its inspectors after finding and due warning about the violation, it have a legal basis for leaving a time that is available for regulation or the implementation of the obligation. Thus, this has been untapped by entrepreneurs seeking measures to remedy the violation. A part of the sanctions that may be imposed on the electronic communications market is the removal of the right to use frequencies or numbering. In addition, it involves the removal of the right to provide services of electronic communications networks.

Therefore, such measures come as an inspector's proposal of monitoring structure and competence. It is used for the purpose of making decisions that belongs to the steering board to decide after the reviewing of the proposals has been made. Hence, this was further done by performing all the necessary notification procedures for entrepreneurs according to the definitions of the Code of Administrative Procedure.

\section{Conclusion}

- Regulatory obligations are instruments in the hands of the regulator to impose the development of competition. It is used to achieve the mission and the regulatory scope for a dynamic market. It is developed in order to increase the maximum benefit of consumers in this market. 
- Regulatory intervention aims to be effective and strategic in its purpose. It harmonizes decision-making of its effects directly in the electronic communications market practices with the legal background and regulatory framework. Thus, this has yielded concrete effects and instruments which are tested and consolidated as "practical regulatory good".

- Legal provisions, primary and secondary, produced through regulatory acts have clearly defined mechanisms and procedures that will identify problem/problems inhibiting the development of competition. It would also provide for specific target period for regularization.

- Legal provisions harmonize and determine the administrative levels and processes necessary to monitor and inspect who follows the sequential implementation of regulatory obligations. It monitors and inspects their possible effect on electronic communications market. It enables and facilitates decision making regulatory for the time necessary for the operation of the obligations imposed, their trial modification, and the rest of them. In addition, it also enables any necessary modifications in relation to the resolution, diminution, or elimination of the problem/problems identified in the market.

\section{References:}

Directive 2009/140 / EC of the European Parliament and of the Council of 25 November 2009 amending Directives 2002/21 / EC on a common REGULATORY framework for electronic communications networks and services, 2002/19 / EC on access to, and interconnection of , electronic communications networks and Associated Facilities, and 2002/20 / EC on the authorisation of electronic communications networks and services Directive 2009/136 / EC of the European Parliament and of the Council of 25 November 2009 amending Directive 2002/22 / EC on universal service and users' Rights relating to electronic communications networks and services, Directive 2002/58 / EC Concerning the processing of personal data and the protection of privacy in the electronic communications sector and Regulation (EC) No 2006/2004 on Cooperation between national Authorities Responsible for the Enforcement of Consumer Protection Laws; Commission Recommendation of 17 December 2007 on relevant product and service Markets Within the electronic communications sector susceptible to ex ante regulation in ACCORDANC with Directive 2002/21 / EC of the European Parliament and of the Council on a common REGULATORY framework for electronic communications networks and services;

Explanatory note Accompanying document to the Commission Recommendation on Relevant Product and Service Markets Within the 
electronic communications sector susceptible to ex ante regulation in ACCORDANC with Directive 2002/21 / EC of the European Parliament and of the Council on a common REGULATORY framework for electronic communications networks and services;

Commission Recommendation of 7 May 2009 on the Regulatory Treatment of Fixed and Mobile Termination Rates in the EU (2009/396 / EC);

Commission Recommendation on the Regulatory Treatment of Fixed and Mobile Termination Rates in the EU explanatory note \{C (2009) 3359 final \{SEC (2009) 599\}

Law no. 9918, dated 19. 05. 2008 "On Electronic Communications in the Republic of Albania" amended;

Code of Administrative Procedure of the Republic of Albania, amended. 